Brit. J. industr. Med., 1951, 8, 14.

\title{
THE EFFECT OF ADHESIVE FILM THICKNESS ON THE SAMPLING EFFICIENCY OF THE KONIMETER
}

BY

\author{
R. J. HAMILTON, T. WAINWRIGHT, and W. H. WALTON \\ From the Central Research Establishment of the National Coal Board
}

(RECEIVED FOR PUBLICATION OCTOBER 3, 1950)

The method at present used in Britain for the preparation of konimeter slides, namely, the application of a film of glycerine jelly with the finger, was felt to be insufficiently controlled to give reproducible results by different operators, and it was therefore decided to test the improved technique recently introduced by the Transvaal Chamber of Mines (1947) which consists of coating the slides with a film of petroleum jelly applied as a solution in xylene.

During the investigation of the different methods of slide preparation a number of unforeseen problems arose. It was found that the appearance of the dust samples varied considerably according to the thickness of adhesive film. Initially it was thought that this might be attributed to inferior optical properties of the thicker films. Further work revealed that, on the contrary, thicker films were giving the truer results, and that thin films of the type hitherto used lead to spurious dust concentration values through the larger particles shattering and rebounding on impact with the slide.

\section{Experimental Work on Film Preparation}

In the South African method of preparation the slide is flooded with a solution of petroleum jelly in xylene and then stood on edge so that surplus liquid may drain off. The residual liquid on the slide evaporates leaving a thin film of jelly over the surface. The thickness of the resulting film is determined by the relative rates of draining and of evaporation. Since the rate of draining diminishes very rapidly as the film gets thinner, this tends to give films of nearly uniform thickness except for a small area at the lower edge where a drop of liquid accumulates. This latter is wiped from the slide after evaporation is complete. This technique was found to be quite satisfactory, being far easier to use than the earlier finger method, and giving films on the slide of great uniformity and consistency of thickness.

By varying the concentration of petroleum jelly (B.P. paraff. moll. flav.; melting point, $38-46^{\circ} \mathrm{C}$.) in the solvent, it was possible to vary the thickness of the film left on the slide within wide limits. For the solvent, both xylene and toluene were used, and proved equally satisfactory, although the different vapour pressures of the two liquids $(10 \mathrm{~mm}$. and $20 \mathrm{~mm}$. $\mathrm{Hg}$ at $20^{\circ} \mathrm{C}$. respectively) caused the film thicknesses to be different, and for the same concentration of jelly, the toluene film was some $50 \%$ thicker than that for the xylene solution.*

Film thickness was determined by weighing, with the exception of the thinnest film, whose thickness

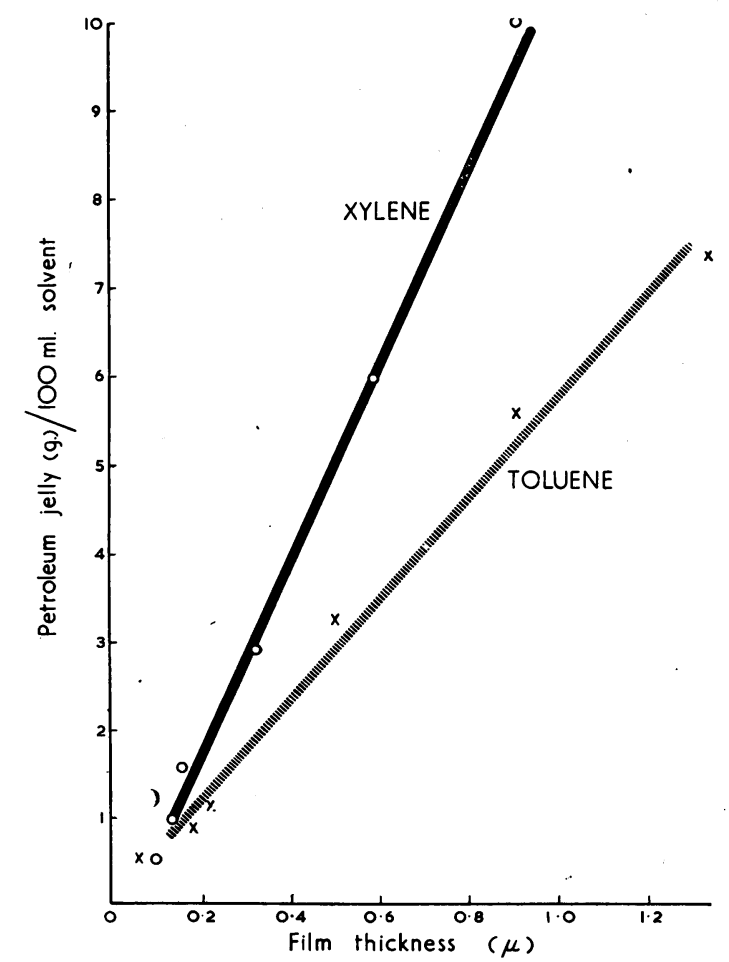

FIG. 1

* Later work has indicated that toluene is preferable to xylene as a solvent. Precipitated particles (possibly of wax) within the films have sometimes been noted when xylene is used. 
was calculated by extrapolation from the graph jelly concentration/film thickness (Fig. 1). An attempt was made to check the uniformity of film



FIG. 2

thickness over the slides by an inter-ferometric method, but optical flats of sufficiently high quality to give accurate results were not available.

\section{Instrument Performance with Films of Different Thicknesses}

A series of tests was carried out with the Watson konimeter using slides with petroleum jelly films of different thicknesses. In each case the test cloud was of coal dust formed by an air-swept tumble mill, as used in previous work in this laboratory. This dust source gave a cloud of excellent short-term constancy, but there was a slow decrease in concentration over prolonged periods. The cloud was relatively free from aggregates. Samples were taken at the end of a 3 in. square section tunnel in an air velocity of $160 \mathrm{ft}$./min., the konimeter being held with the jet at right angles to the direction of air flow. A Witwatersrand konimeter was used to check the constancy of the cloud during a run, the Watson konimeter slides being changed in order that the different film thicknesses might be tested. Both bituminous coal and anthracite were used in different runs.

The counting of the dust spots was carried out on the Vickers projection microscope, using a $16 \mathrm{~mm}$. objective and $\mathrm{x} 4$ projector giving an overall magnification of $\times 200$ on the screen. A screen graticule of the same design as that in the Watson konimeter microscope was used. Counts were made of the numbers of particles greater and less than $5 \mu$ diameter respectively.

Four series of tests were carried out. The results are tabulated in Tables 1 to 3 and shown graphically in Fig. 2. In the first run of the first series (Table 1, p. 16) seven film thicknesses in the range $0.06 \mu$ to $3 \mu$ were tested using bituminous coal dust. Only particles smaller than $5 \mu$ were counted in this

TABLE 2

RESULTS OF KONIMETER COUNTS IN RELATION TO FILM THICKNESS

\section{B. Soft Bituminous Coal}

\begin{tabular}{|c|c|c|c|c|c|c|}
\hline \multirow[t]{2}{*}{ Slide } & \multirow{2}{*}{$\begin{array}{l}\text { Concen- } \\
\text { tration } \\
\text { (Jelly } \\
\text { g./100 ml. } \\
\text { xylene) }\end{array}$} & \multirow{2}{*}{$\begin{array}{l}\text { Film } \\
\text { Thick- } \\
\text { ness } \\
(\mu)\end{array}$} & \multicolumn{2}{|c|}{$\begin{array}{l}\text { Konimeter } \\
\text { Counts }\end{array}$} & \multicolumn{2}{|c|}{$\begin{array}{c}\text { Average } \\
\text { Konimeter } \\
\text { Counts }\end{array}$} \\
\hline & & & $>5 \mu$ & $<5 \mu$ & $>5 \mu$ & $<5 u$ \\
\hline$\underset{\mathrm{A}}{R u n} 3$ & 0.5170 & $0 \cdot 1$ & $\begin{array}{l}30 \\
22 \\
30 \\
16\end{array}$ & $\begin{array}{l}824 \\
662 \\
948 \\
792\end{array}$ & 24 & 806 \\
\hline B & 0.9854 & $0 \cdot 14$ & $\begin{array}{l}42 \\
46 \\
50 \\
44\end{array}$ & $\begin{array}{l}692 \\
762 \\
934 \\
734\end{array}$ & 46 & 781 \\
\hline $\mathrm{C}$ & $1 \cdot 5954$ & $0 \cdot 16$ & $\begin{array}{l}68 \\
58 \\
40 \\
58\end{array}$ & $\begin{array}{l}796 \\
688 \\
816 \\
724\end{array}$ & 52 & 756 \\
\hline D & $2 \cdot 9994$ & $0 \cdot 33$ & $\begin{array}{l}94 \\
78\end{array}$ & $\begin{array}{l}718 \\
704\end{array}$ & 86 & 711 \\
\hline$E$ & 5.9990 & 0.6 & $\begin{array}{l}120 \\
124 \\
142 \\
119\end{array}$ & $\begin{array}{l}459 \\
364 \\
364 \\
338\end{array}$ & 126 & 378 \\
\hline$F$ & $9 \cdot 9978$ & 0.9 & $\begin{array}{r}90 \\
130 \\
132 \\
132\end{array}$ & $\begin{array}{l}338 \\
496 \\
400 \\
422\end{array}$ & 121 & 414 \\
\hline
\end{tabular}

case. The most striking feature of the results is a sudden fall in the particle count, by about $40 \%$, as the film thickness is increased from $0.5 \mu$ to $1 \mu$. 
TABLE 1

RESULTS OF KONIMETER COUNTS IN RELATION TO FILM THICKNESS

A. Bituminous Coal

\begin{tabular}{|c|c|c|c|c|c|}
\hline Slide & $\begin{array}{l}\text { Concentration } \\
\text { (Jelly g./100 ml. } \\
\text { toluene) }\end{array}$ & $\begin{array}{l}\text { Mass of Film } \\
\text { (g.) }\end{array}$ & $\begin{array}{c}\text { Film } \\
\text { Thickness } \\
(\mu)\end{array}$ & $\begin{array}{l}\text { Konimeter } \\
\text { Counts } \\
(<5 \mu)\end{array}$ & $\begin{array}{c}\text { Average } \\
\text { Konimeter } \\
\text { Counts }\end{array}$ \\
\hline$\underset{a}{R u n} 1$ & 0.548 & 0.0002 & 0.059 & $745 ; 649 ; 862 ; 789$ & 762 \\
\hline$b$ & 0.925 & 0.0003 & 0.089 & $659 ; 780 ; 639 ; 718$ & 699 \\
\hline$c$ & $1 \cdot 1686$ & 0.0007 & $0 \cdot 208$ & $786 ; 632 ; 866$ & 746 \\
\hline$d$ & $3 \cdot 231$ & 0.0017 & $0 \cdot 505$ & $706 ; 770 ; 694$ & 723 \\
\hline$e$ & $5 \cdot 582$ & 0.0031 & 0.921 & $406 ; 406 ; 563 ; 488$ & 466 \\
\hline$f$ & $7 \cdot 445$ & 0.0043 & $1 \cdot 28$ & $469 ; 412 ; 459 ; 421$ & 440 \\
\hline$g$ & 8.934 & 一 & - & 一 & 一 \\
\hline$h$ & $14 \cdot 890$ & $0 \cdot 0100$ & $2 \cdot 97$ & $404 ; 306 ; 349 ; 451$ & 398 \\
\hline $\operatorname{Run}_{l} 2$ & $0 \cdot 101$ & 一 & 0.009 & 483 & - \\
\hline$m$ & $0 \cdot 311$ & 一 & 0.029 & 583 & 一 \\
\hline$n$ & $1 \cdot 058$ & - & $0 \cdot 100$ & 600 & - \\
\hline \multicolumn{3}{|c|}{ Witwatersrand konimeter (control) } & $0 \cdot 230$ & $811 ; 787 ; 755$ & - \\
\hline
\end{tabular}

TABLE 3

RESULTS OF KONIMETER COUNTS IN RELATION TO FILM THICKNESS

C. Anthracite

\begin{tabular}{|c|c|c|c|c|c|c|c|}
\hline \multirow{2}{*}{ Slide } & \multirow{2}{*}{$\begin{array}{c}\text { Film } \\
\text { Thickness } \\
(\mu)\end{array}$} & \multicolumn{3}{|c|}{ Konimeter Count } & \multicolumn{3}{|c|}{ Average Konimeter Counts } \\
\hline & & $>10 \mu$ & $>5 \mu$ & $<5 \mu$ & $>10 \mu$ & $>5 \mu$ & $<5 \mu$ \\
\hline${ }_{\mathrm{G}}{ }_{\mathrm{G}}^{4}$ & $0 \cdot 1$ & $\begin{array}{r}4 \\
-\end{array}$ & $\begin{array}{l}46 \\
56\end{array}$ & $\begin{array}{l}766 \\
702\end{array}$ & $\underline{2}$ & 51 & $\frac{734}{-}$ \\
\hline $\mathbf{H}$ & $0 \cdot 14$ & $\overline{4}$ & $\begin{array}{l}74 \\
56\end{array}$ & $\begin{array}{l}934 \\
908\end{array}$ & $\overline{2}$ & $\overline{65}$ & $\overline{921}$ \\
\hline I & 0.33 & $\begin{array}{r}6 \\
10 \\
2\end{array}$ & $\begin{array}{r}158 \\
98 \\
150 \\
140\end{array}$ & $\begin{array}{r}1054 \\
756 \\
962 \\
968\end{array}$ & $\frac{-}{4}$ & $\frac{-}{137}$ & $\overline{-}$ \\
\hline $\mathbf{J}$ & $0 \cdot 6$ & $\begin{array}{l}22 \\
18 \\
14 \\
22\end{array}$ & $\begin{array}{l}248 \\
198 \\
158 \\
220\end{array}$ & $\begin{array}{l}754 \\
622 \\
660 \\
474\end{array}$ & $\frac{-}{19}$ & $\underline{-}$ & $\frac{-}{652}$ \\
\hline
\end{tabular}


This fall was accompanied by a marked change in the appearance of the dust, as shown in Figs. 3, 4, 5 , and 6. With the thickest film, many large particles up to $20 \mu$ in diameter were seen of which there was no trace with the thinner films.

The second run (Table 1) was carried out with very thin films, $0 \cdot 009 \mu$ to $0 \cdot 1 \mu$ thick. It shows that the particle count diminishes when the films are made too thin, as would be expected.

Runs 3 and 4 (Tables 2 and 3) were made with a soft bituminous coal and with anthracite respectively, and particles both larger and smaller than $5 \mu$ were counted. Unfortunately, film thickness greater than $0 \cdot 6 \mu$ was not used in the last test. In each case, however, the general trend of the $<5 \mu$ count was similar to that already noted ; there was a large diminution in the number of small particles as the film thickness approached $1 \mu$. This fall was accompanied by a very large rise in the number of large particles $(>5 \mu)$ on the slide, the increase being approximately fivefold.

Two explanations of these results appeared possible. (1) That with thick films small particles were being buried so that they could not be resolved by the microscope and that the film itself was being broken by the air jet with the formation of dustfilled irregularities having the appearance of large particles ; (2) that large particles in part shattered on impact with the slide when the film was thin, giving rise to an increased fine particle count, and in part rebounded from the slide and were lost from the sample.

Further experiments were therefore made to decide between these alternative possibilities.

TABLE 4

RESULTS OF KONIMETER COUNTS OF INDIAN INK PARTICLES

\begin{tabular}{|c|c|c|c|c|}
\hline \multirow{2}{*}{$\begin{array}{c}\text { Slide } \\
\overline{R_{\mathrm{K}}}(a)\end{array}$} & \multirow{2}{*}{$\begin{array}{c}\begin{array}{c}\text { Film } \\
\text { Thickness } \\
(\mu)\end{array} \\
0.1\end{array}$} & \multicolumn{2}{|c|}{$\begin{array}{c}\text { Konimeter } \\
\text { Count }\end{array}$} & \multirow{2}{*}{ Average } \\
\hline & & $\begin{array}{l}191 \\
217 \\
242\end{array}$ & $\begin{array}{l}140 \\
195 \\
219\end{array}$ & \\
\hline $\mathbf{L}$ & 1.0 & $\begin{array}{l}227 \\
182 \\
191\end{array}$ & $\begin{array}{l}129 \\
181 \\
139\end{array}$ & 192 \\
\hline$\underset{\mathrm{M}}{\operatorname{Run}(b)}$ & $0 \cdot 1$ & $\begin{array}{l}232 \\
275 \\
281\end{array}$ & $\begin{array}{l}274 \\
221 \\
177\end{array}$ & 237 \\
\hline $\mathbf{N}$ & 1.0 & $\begin{array}{l}189 \\
185 \\
143\end{array}$ & $\begin{array}{l}370 \\
155 \\
216\end{array}$ & 211 \\
\hline
\end{tabular}

\section{Konimeter Counts in the Absence of Large Particles}

The first experiment was designed to show whether the count obtained varied with the film thickness in the absence of large particles. Konimeter samples were taken of a cloud of solid indian ink particles of size $<3 \mu$ formed by the evaporation of a sprayed solution. Two film thicknesses were used, $1 \mu$ and $0 \cdot 1 \mu$, and the counts now indicated a much smaller diminution in the number of particles visible on the thicker film, although the spots on the two films differed in appearance, that on the $1 \mu$ film having a more concentrated central zone. The results are detailed in Table 4.

\section{Depth of Penetration}

The depth of penetration of particles into petroleum jelly films was investigated at larger sizes by shooting small spheres of sealing wax at a

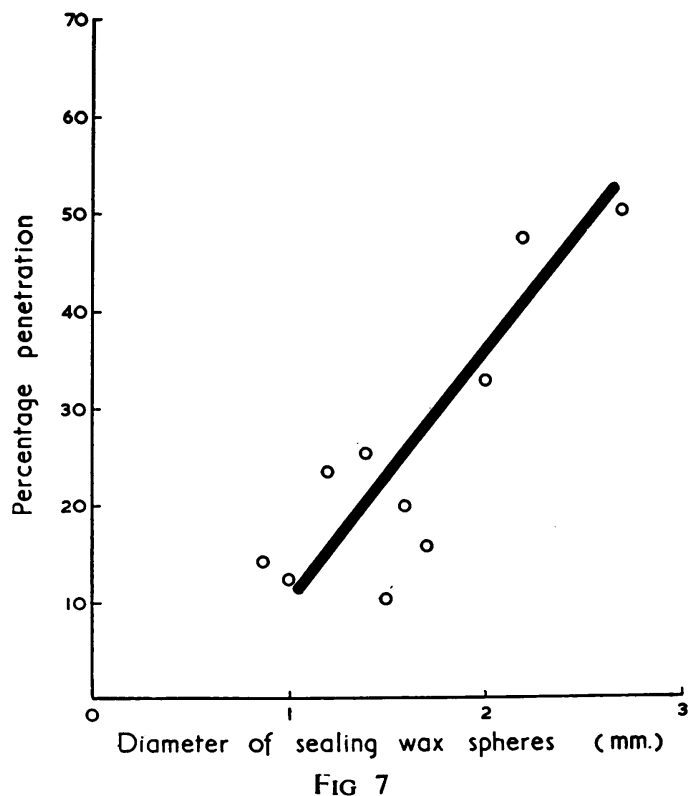

jelly surface. These spheres were formed by fusing powdered sealing wax on a cold surface by flaming the particles with a Bunsen burner. The spheres were then introduced via a side arm into a long glass tube through which air was blown at $80 \mathrm{~m}$. $/ \mathrm{sec}$., this being the value given by the makers for the velocity in the jet of the konimeter. The depth of penetration of the particles into the jelly, expressed as a percentage of the particle diameter, was calculated from microscopic measurements of the diameter and height of particle remaining above the surface. The resulting plot of penetration and particle size (Fig. 7) shows considerable scatter due 


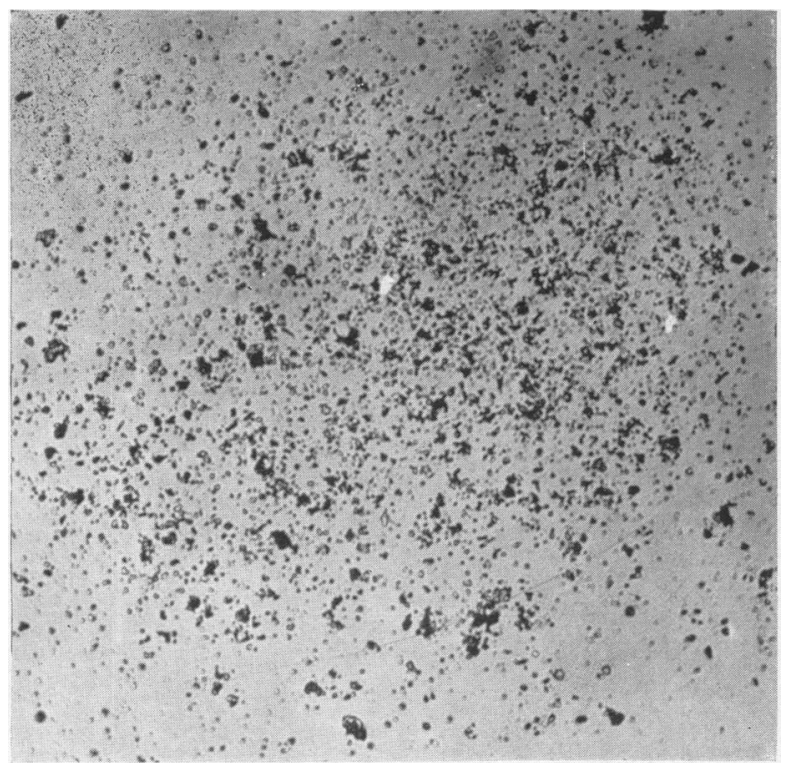

FIG. 3.-Film thickness $0 \cdot 1 \mu$.

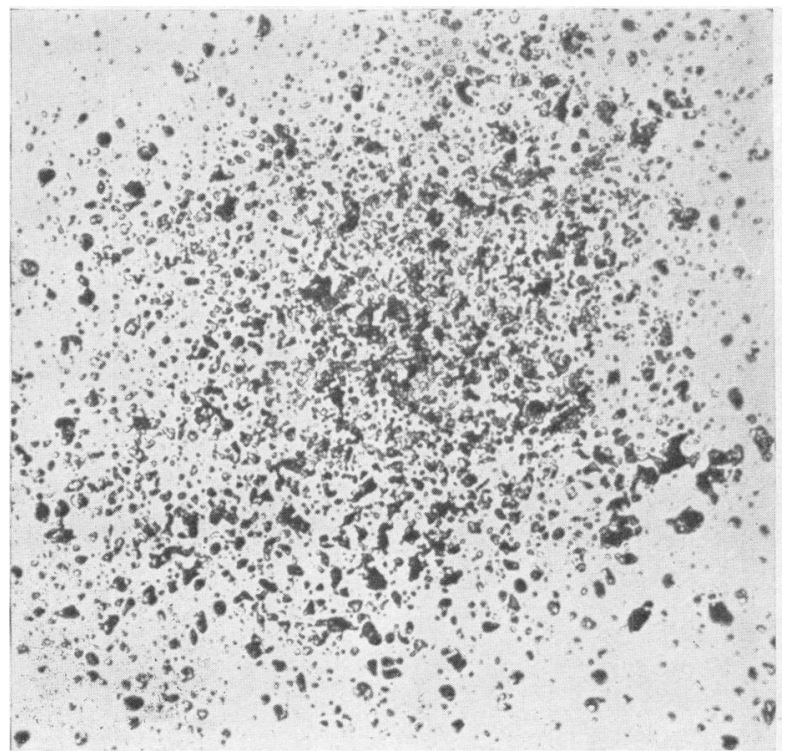

FIG. 5.-Film thickness $0.35 \mu$.
Figs. 3-6.-Photomicrographs illustrating marked change in the appearance of the dust after sudden fall in the particle count.

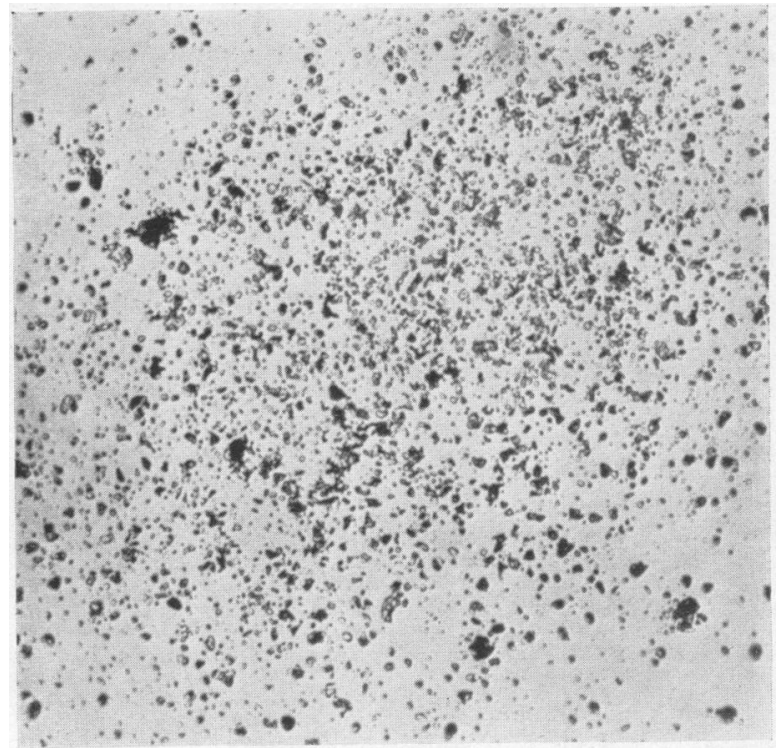

Fig. 4.-Film thickness $0 \cdot 15 \mu$.

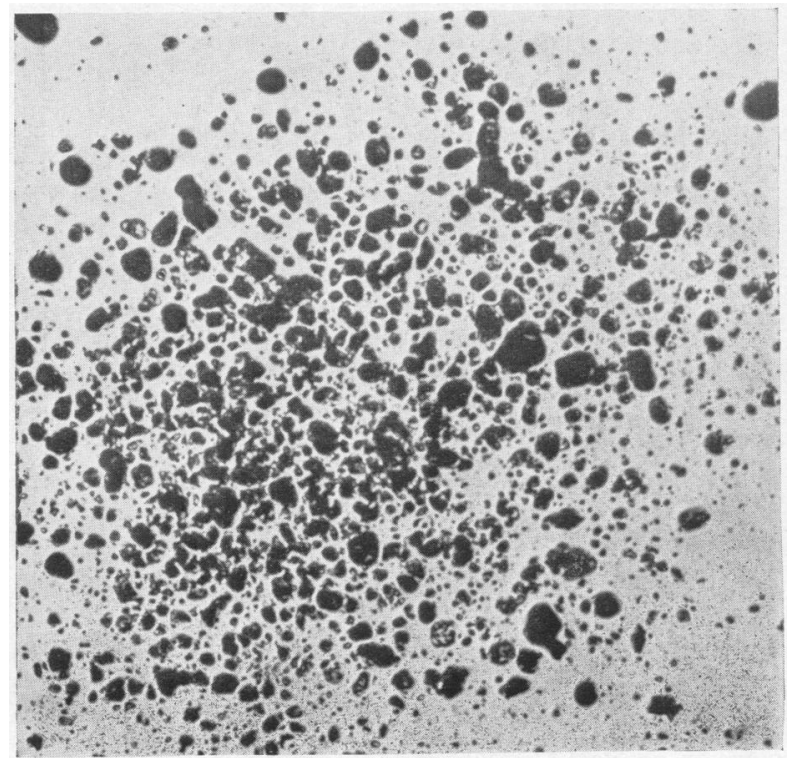

Fig. 6.-Film thickness $0.9 \mu$. 
to the method of measurement and the imperfect sphericity of the particles, but it clearly demonstrates that the percentage penetration is small and diminishes as the particle size grows smaller. Particles evidently remain on the surface of the adhesive film and it appears most improbable that deep penetration of small particles into the film can detract from the accuracy of konimeter counts. Indeed, although the results in Fig. 7 cannot be extrapolated to particles of the size sampled by the konimeter, they do suggest that the fall in konimeter count of $<5 \mu$ particles when the film thickness approaches $1 \mu$ occurs when the larger particles cease to penetrate the film and to strike the glass plate beneath. This view was reinforced by shooting $\frac{1}{4}$ in. diameter coal particles, in the manner described for sealing wax spheres, at petroleum jelly films on glass. No shatter occurred unless the particles penetrated to the back-plate, but when they did strike the glass the break-up was usually extensive. There was also a rebound of large fragments.

\section{Rebound of Particles}

The possibility of particles rebounding from the slide in the konimeter was examined by applying an adhesive film to the brass surface surrounding the lower end of the jet, which is at a distance of $0.5 \mathrm{~mm}$. from the glass slide. It was thought that particles rebounding from the slide might strike and be retained on this surface, and this in fact was found to be so. Fig. 8 gives counts of the numbers of particles on the slide and jet respectively for various film thicknesses. The curves for the numbers of large and small particles on the slide follow the pattern already described. The number of particles caught on the adhesive surface surrounding the jet decreased with increasing film thickness and the slide's efficiency in retaining large particles.

\section{Types of Film}

The experiments we have described show that the performance of the konimeter in sampling coal dusts is very dependent on the thickness of the adhesive film, and it is therefore of interest to know the type of film that has hitherto been generally employed. These have been of glycerine jelly applied with the finger, but no standard thickness has been employed and there can be little doubt that there have been wide variations. The usual practice appears to have been to use very thin films and the instructions supplied by the makers of the British type of konimeter state that surplus adhesive should be removed " until only a very thin film in the form of a tarnish remains on the plate".

The weight of film on a number of slides prepared in this manner in the laboratory has been determined. We found that the values ranged from $0.4 \mathrm{mg}$. to $6 \mathrm{mg}$. corresponding to film thicknesses of from
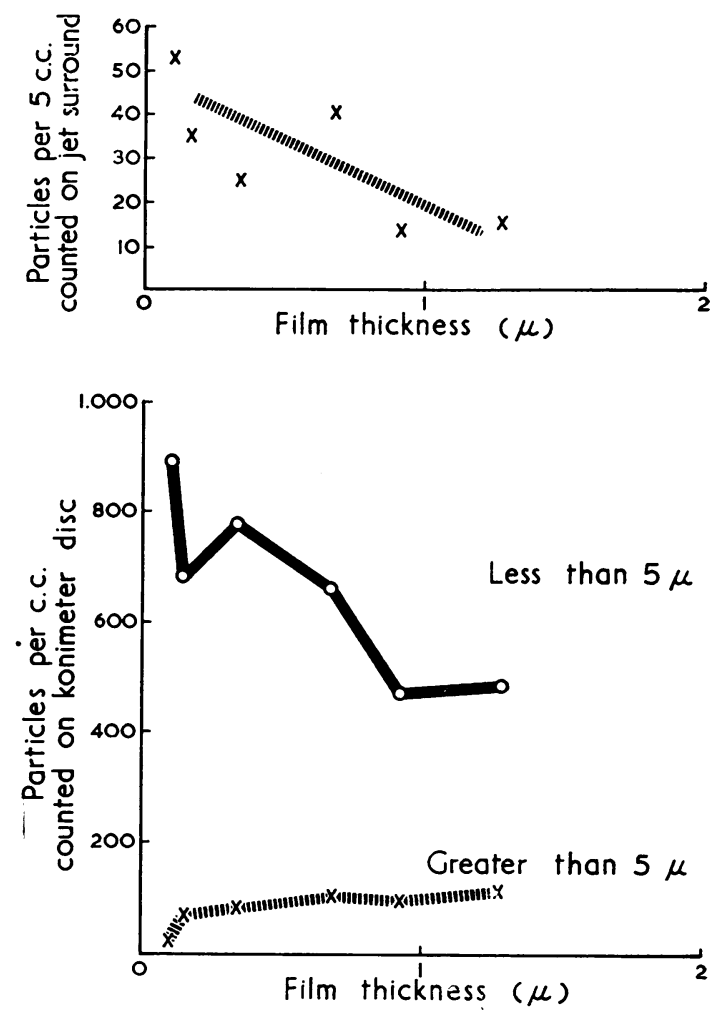

FIG. 8

$0 \cdot 12 \mu$ to $1 \cdot 8 \mu$ respectively. Two other laboratories, with considerable experience of konimetry have given the following data for slides prepared: (a) ten films varying from 0.3 to $0.9 \mathrm{mg}$. weight, with an average of $0.65 \mathrm{mg}$., corresponding to thicknesses of $0.09 \mu, 0.3 \mu$, and $0.2 \mu$ respectively ; (b) three films of weights $0.2 \mathrm{mg}$., $0.7 \mathrm{mg}$., and $0.9 \mathrm{mg}$., with corresponding thicknesses of $0.06 \mu$, $0 \cdot 2 \mu$, and $0 \cdot 3 \mu$.

South African practice in this older method of slide preparation is to use a film of such thickness that the weight of glycerine jelly spread over an area $5 \mathrm{~cm}$. in diameter should be approximately $0.5 \mathrm{mg}$. Assuming the density to be unity, this corresponds to a thickness of $0 \cdot 25 \mu$. It therefore appears that the general practice, both in this country and in South Africa, has been to use films of the type which gave high small particle counts in Fig. 2. The South African instructions for slide preparation by the improved technique using petroleum jelly in xylol do not specify the film thickness, but give 
the concentration of solution to be used as $1 \% \mathrm{w} / \mathrm{v}$. Reference to Fig. 1 indicates that this would give a $0 \cdot 14 \mu$ film, so that " thin films" appear still to be used in that country.

\section{Discussion}

Our experimental evidence leads clearly to the following conclusions.

The South African improved technique of konimeter slide preparation using a solution of petroleum jelly in xylene gives films of excellent quality and reproducibility and is easy to use. The method is superior to the older one in which glycerine jelly is applied with the finger.

When clouds of coal dust are sampled with the konimeter, the particle count obtained varies markedly according to the thickness of adhesive film on the slide. In the experiments reported, the count of $<5 \mu$ particles fell sharply by about $40 \%$ as the film thickness was increased from $0.4 \mu$ to $1 \mu$. The count of $5 \mu$ particles increased fivefold as the film thickness was increased in the range $0 \cdot 1 \mu$ to $1 \mu$.

The results obtained in the work described in this report may be illustrated approximately (Fig. 9).

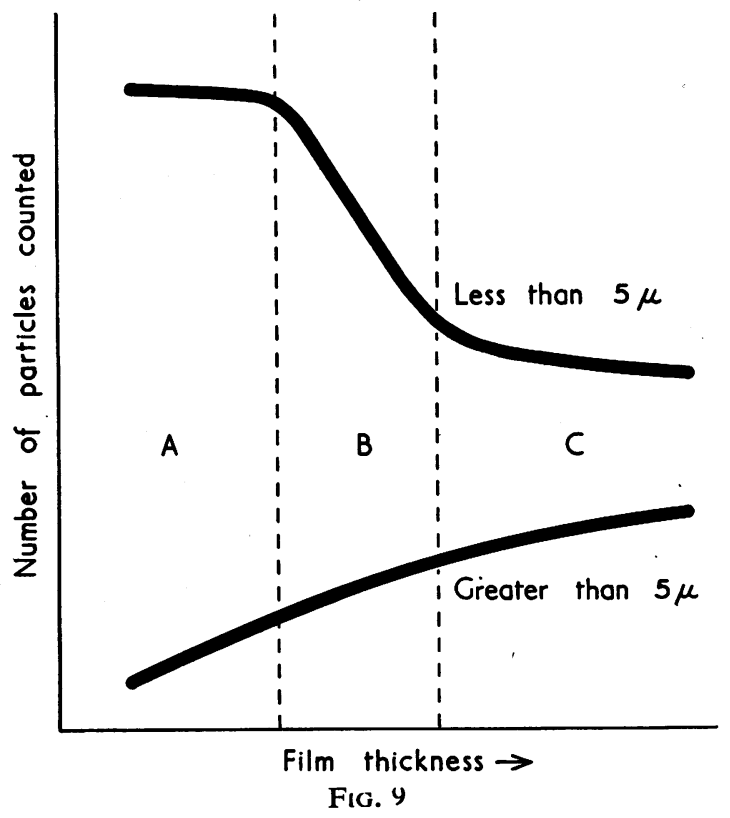

In zone $\mathrm{A}$, which covers roughly film thicknesses of from $0.1 \mu$ to $0.25 \mu$, the counts of fine particles remain approximately constant at a high level, and the counts of large particles gradually increase. These effects are due predominantly to the shatter and rebound of large particles. In zone $B$, which extends roughly over the film thickness of from
$0.25 \mu$ to $0.8 \mu$, the counts of fine particles diminish considerably, and those of large particles increase. Here shatter of large particles is ceasing rapidly with increase in film thickness. In zone $C$ the number of fine particles counted remains approximately constant with further increase in film thickness owing to the complete cessation of shatter, and the number of large particles also shows little change, although there is evidence that rebound of very large particles $(>10 \mu)$ takes place from films of thickness greater than $1 \mu$. Hence it will be seen that the thicker films are giving a more accurate measure of the sampled cloud than are the "thin" films of about $0 \cdot 25 \mu$.

It is estimated that the glycerine jelly films which have conventionally been used hitherto have been of the order of $0.25 \mu$ thick or less, and hence it appears probable that counts have been recorded for the small particles which are consistently too high. The magnitude of the error with thin films will depend on the number of large particles present in the sampled cloud. It is not known whether film thickness is of equal importance in sampling rock dusts, which may be more resistant to shatter.

The use of thicker films will improve the accuracy of the konimeter as a sampling instrument only in so far as it reduces the generation of spurious fine particles within the instrument itself by shatter and increases the retention of larger particles on the slide. Other inherent limitations of the konimeter, arising from its snap action and the failure of very small particles to impinge, are unaffected. Davies, Aylward, and Leacey (1951) have reported that konimeter deposits contain a large number of fine particles not present in the original cloud, and attributed this to the disintegration of aggregates in the jet. Such disintegration will be unaffected by film thickness.

Various workers in recent years have investigated the correlation between the konimeter and other dust-sampling instruments. Burdekin (1948), using a constant laboratory coal dust cloud, found that the particle concentration measured by the Watson konimeter agreed with that given by the thermal precipitator in the size range $0.9 \mu$ to $5 \mu$. Beadle (private communication) for rock dust in the South African gold mines, has given the following results for the Kotze konimeter.

\begin{tabular}{c|c}
\hline $\begin{array}{c}\text { Percentage }>2 \mu \text { by } \\
\text { Thermal Precipitator }\end{array}$ & $\begin{array}{c}\text { Ratio of Konimeter Count/ } \\
\text { Thermal Precipitator } \\
\text { Count }\end{array}$ \\
\hline $1-3$ & $0 \cdot 26$ \\
$3-13$ & 0.80 \\
$14-18$ & 0.91 \\
$19-29$ & 1.33 \\
\hline
\end{tabular}


Thus the number of particles found by konimeter is only a fraction of that given by the thermal precipitator when no large particles are present, but rises above the thermal precipitator value when the cloud is coarse. This can be explained by the generation of small particles from large ones in the konimeter, either by disruption of aggregates or by shatter. Burdekin (private communication) has further stated that the size distribution of particles used in his experiments mentioned above makes his results consistent with those of Beadle.

Davies, Aylward, and Leacey investigated the performance of a number of different types of impingement instruments, including the Kotze and Watson konimeters. Test clouds of both coal and quartz were used. which were probably rather more highly aggregated than those used in our work. Their experiments were not made with clouds of different size distributions, but it was attempted to calculate instrument performance for each size from the size analysis of the counts. For coal dust it was found that the konimeter efficiency increased with decrease in size, being greater than unity below $1.5 \mu$ and rising to several hundreds per cent. at smaller sizes. Above $1.5 \mu$ the Watson konimeter efficiency tailed off rapidly to zero at $8 \mu$. In the same size range the Kotze konimeter efficiency remained near unity. These results were for slides coated with glycerine jelly applied by the finger to give a very thin film. Coated slides were not used in the work with quartz dust.

There can be little doubt that all the work described in the preceding paragraphs is seriously affected by the film thickness used on the slides, and this was largely undefined in what was otherwise careful work. In each case the films were probably in the thin category (about $0.25 \mu$ ) described in this report. Had thicker films (about $1 \mu$ ) been used, it seems probable that the very high counts of small particles when large ones were also present would not have been obtained, and that the overall konimeter counts would have been appreciably reduced in relation to those obtained with the thermal precipitator.

Since the performance of the konimeter as a (coal) dust-sampling instrument varies greatly with the nature of the adhesive film on the slide, it is evident that a standardized method of film preparation is desirable. We suggest that petroleum jelly films $1 \mu$ thick, applied by the solvent method, should be adopted as standard. At this thickness spurious counts arising from the shatter and bounce of particles on impact with the slide are largely eliminated, although other limitations of the instrument remain.

\section{Summary}

The South African technique of preparing adhesive films on konimeter slides from a solution of petroleum jelly in xylene has been tested and found to give results of excellent reproducibility and uniformity. It is considered to be superior to the method in which glycerine jelly is applied with a finger.

The performance of the konimeter in sampling coal dust is considerably influenced by the thickness of adhesive film on the slide. Thin films (about $0.25 \mu$ ) as conventionally used, give an exaggerated fine particle count and low estimate of the number of large particles, as a result both of the shatter and the rebound of the latter on impact with the slide. Thicker films (about $1 \mu$ ) provide a cushioning effect which largely eliminates these errors.

We wish to thank Dr. J. T. Burdekin and Mr. F. Henley Price for providing information on film thickness for slides prepared in their laboratories.

This paper is published by permission of the Director General, Scientific Department, National Coal Board.

\section{REFERENCES}

Burdekin, J. T. (1948). Colliery Guard., 177, 869

Davies, C. N.. Aylward, M., and Leacey, D. (195i). In the press. Transvaal Chamber of Mines (1947). Quality of Mine Air. Johannesburg. 